\title{
Research Paper \\ Analysis of Participatory Need Measurement for Establishment of Rural Communities Based Management (Case Study: Bozijan Village, Mohallat District, Markazi Province)
}

\author{
*Mehdi Ghorbani ${ }^{1}$, Jamileh Salimi Kochi², Payam Ebrahimi ${ }^{2}$
}

1- Associate Professor, Department of Reclamation of Arid and Mountainous Regions, Faculty of Natural Resources, College of Agriculture \& Natural Resources, University of Tehran, Tehran, Iran.

2- PhD Candidate, Department of Reclamation of Arid and Mountainous Regions, Faculty of Natural Resources, College of Agriculture \& Natural Resources, University of Tehran, Tehran, Iran.

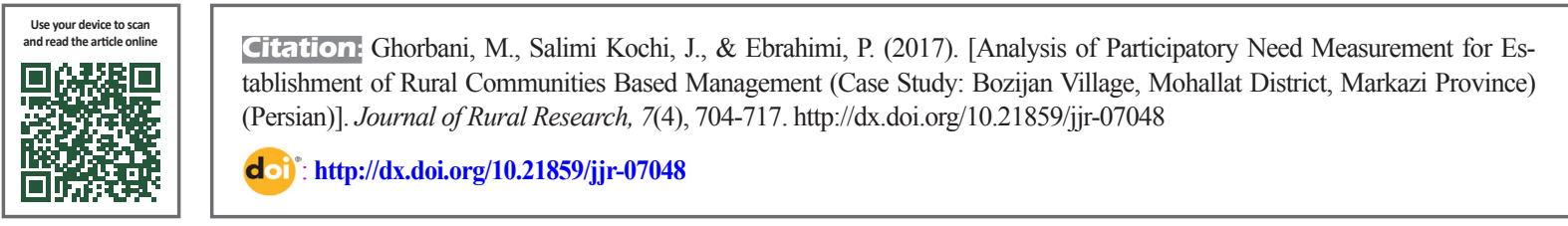

Received: 04 Sep. 2016

Accepted: 15 Nov. 2016

Keywords:

Need assessment,

Bozijan village,

Community-based

management,

Participatory work-

shop, AHP

\begin{abstract}
A B STRACT
Participatory need measurement is a process based on community-based management approach, which focuses on different aspects of local communities' needs. The project of Iranian model for participation and empowerment of local communities with social networks approach is a step towards developing an action plan in Bozijan Village, Mahallat District, Markazi Province. Priorities and needs assessment of problems and challenges is one of the most important principles in rural planning. For this purpose, using qualitative methods such as group discussion and brainstorming, we defined the challenges of participatory activities and then using AHP method, we prioritized rural development issues in view of local stakeholders. The results showed that on the basis of AHP in men and women groups, no range license to take advantage of the rangeland and lack of suitable employment of women, with the highest priority, $15 \%$ of men's needs and $29 \%$ of women's needs had highest priority . In this study all problems from the perspective of local stakeholders (men and women) were identified and prioritized, which can be the basis for planning and policy making to achieve comprehensive development in rural areas.
\end{abstract}

\section{Extended Abstract}

\section{Introduction}

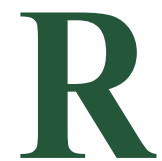

ural development programs are part of every country's development plans used for socio-economic transformation of rural communities. Social capital is a low-cost and reliable method to achieve sustainable rural development. Putnam (1993) believed that social capital was a set of concepts such as trust, norms, and networks that lead to communi- cation and optimized collaboration between members of a community and ultimately would ensure their mutual interests. Social capital is fundamental to social empowerment of local communities and is considered as one of the most important sociological concepts in the cooperative management of the land, and used as a key factor in the process of community-based management approach in rural development. Collaboration is one of the basic elements of social capital and also missing and fundamental aspect of sustainable development in rural areas. Achieving rural sustainable development without adopting the attitude towards popular participation is not pos-

\section{* Corresponding Author:}

Mehdi Ghorbani, PhD

Address: Department of Reclamation of Arid and Mountainous Regions, Faculty of Natural Resources, College of Agriculture \& Natural Resources, University of Tehran, Tehran, Iran.

Tel: +98 (912) 7695257

E-mail: mehghorbani@ut.ac.ir 
sible. Participation that is concerned in rural development is developmental participation. This kind of participation covers all levels of society, its needs and dimensions of individual and group life. In traditional structures of rural development, people participation was less considered but in recent years successful projects in rural development have done with people participation and today the word of collaboration is one of fundamental parts in rural development culture.

\section{Methodology}

One of the tools for implementing the real participation of rural communities in the formulation of policies and the implementation of rural development projects are social facilitation techniques. This technique generally emphasizes on Participatory Rural Appraisal (PRA) method and quantitative methods for production the information. PRA method can enhance the villagers' comprehension to understand their problems and opportunities and control their choices and programs and to start the process of participation that can be continued through the implementation of programs or local initiatives management and community control over government plans. This study focused on the needs assessment in achieving sustainable rural development and needs prioritization is determined based on local communities' ideas with qualitative methods such as group discussions and brainstorming. This study carried out in Bozijan village, Bagher Abad district, Mahallat Township, Markazi Province. The main job in this village is animal husbandry and agriculture. There are 8 wells in the village that generally is used for agricultural operation. The amount of irrigated land in the village is low and the water resources include springs, wells, and qanat. The problems of this sector are waste water through the canals and problems along the qanat.

The project of Iranian model for participation and empowerment of local communities with social network approach have been implemented in Bozijan village aimed at land integrated and sustainable management and sustainable rural development. In this project for the first time the new structure as "Land Integrated Management Committee (LIMC)" has been established for policy making in Mahallat Township. In addition to this committee, sustainable rural development fund (micro-credit fund) was established to mobilize financial resources with community participation. The number of male members of this micro-credit fund is 74. The executive project focused on rural empowerment and setting up micro-credit fund, and participation of local communities is necessary in order to achieve this goal. For social empowerment and strengthening of social capital, it is necessary to analyze the pattern of relationships between actors and studying the structure of the relationships in networks at different levels. In this project, social network analysis (SNA) was used to empower local communities and their participation in the sustainable rural development to assess the stability of relations and inter-group social capital.

Therefore, in this project, participatory needs assessment workshops, including social and resource mapping, rural circulation, extraction routine-quarterly, assessing changes routine, problems trees, and prioritize the problems. In order to perform this research, facilitation team with continuous presence in Bozijan village and provide the necessary training to any of the head groups formed in the project, and prioritization was done by AHP. Using numbers from the matrix of pair wise comparison group of men and women in rural areas, the results of the needs assessment workshop were fed into EXPERT CHOICE software, and needs prioritization was determined.

In this study, using qualitative methods such as group discussion and brainstorming, the participatory problems were determined and using AHP, rural development priorities were determined and for the first time in Iran, needs determination was carried out in a smaller level with advanced training to stakeholders in order to determine participatory and mathematical needs.

\section{Results}

The results showed that on the basis of AHP concept, in men and women groups, lack of range license to take advantage of the rangeland (15\% of men needs) and lack of suitable employment of women (29\% of women needs), are the high priorities. In this study all the problems from the perspective of local stakeholders (men and women) were identified and prioritized, which can be the basis for planning and policy making to achieve comprehensive development in rural areas.

\section{Discussion}

Cooperative need assessment of villagers in Bozijan is a coordinated system for empowerment of local communities based on a successful national pattern of definite strategies and policies in the context of rural communitybased management. Once needs of local beneficiaries are correctly and timely pinpointed, proper decisions will be feasible. Accordingly, in the present project, a precise qualitative need assessment was done and local communities were educated about AHP concept. It was for the first time in Iran that a measure beyond local experts, decisions was taken and by educating beneficiaries, cooper- 
ative and mathematical need assessment occurred. It was found that paving the way for building trust and cooperation of villagers, so that they feel their essential role in the community, helps projects, which demands cooperation of villagers, proceed in shorter time and at lower cost. Holding cooperation workshops for need assessment can enhance active presence of rural communities in decision making. Specifying needs and educating AHP concept to villagers and generating a kind of literature which fills the communicative gap between local communities and experts is a difficult task but creates a common language and facilitates achieving organizational goals.

Satisfaction of villagers by experts who could correctly specify their needs and trusting them in this regard, encourages implementation of cooperative projects. Local communities' participation, especially at alternating livelihood structures is an approach extracted out of cooperative workshops. With an emphasis on this approach, we attempted in the present study to increase local communities' participation in need assessment, decision making, and implementation phase of the project. To what extent need assessment corresponds with rural community depends on the presence of experts and their advice for correctly selecting biological criteria. Therefore, indigenous knowledge of Bozijan inhabitants about their environment and their participation in need assessment workshops help reaching higher goals. The present study emphasizes on grass root participation as the basis of social development and introduces it as an efficient instrument.

\section{Conclusion}

If need assessment is done in such a way that leaves positive sense of satisfaction in collective memory, the whole local community will be extremely satisfied. Besides, community-based participation propels empowerment which in turn leads to active participation of local communities for solving problems that had driven failure of a specific policy or approach and therefore resilience of local communities will enhance. It is recommended that the needs of villagers are provided in each project since sympathy of villagers with the project encourages them to pay more attention to the goals of project and this sense of sympathy along with the sense of responsibility is a giant leap and internal drive which secures achievements of management objectives. 


\title{
تحليل نيازسنجى مشاركتى در زمينه استقرار مديريت اجتماع محور روستايى (منطقه بروسىشده:

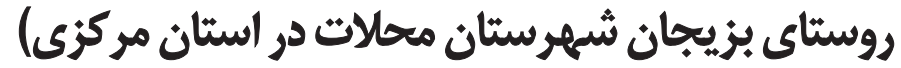

\author{
"مهدى قربانى'، جميله سليمى كوجى'، ييام ابراهيمى'
}

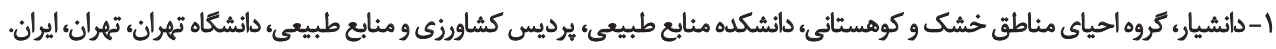

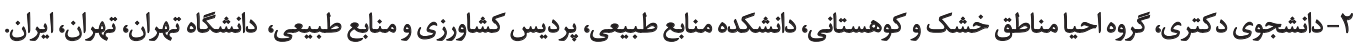

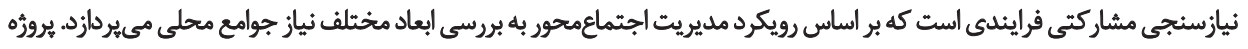

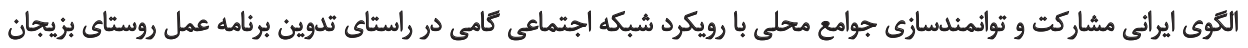

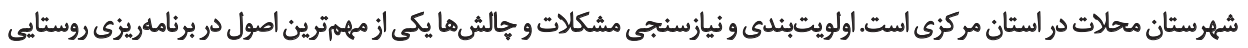

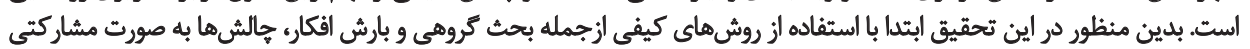

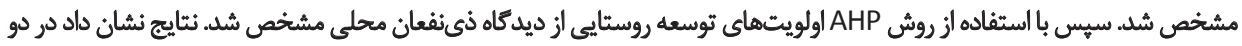

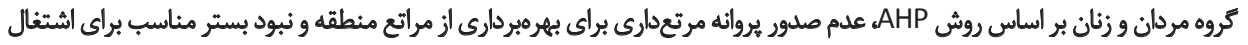

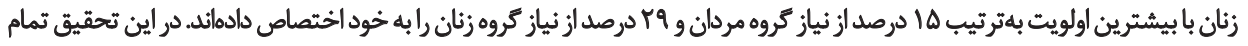

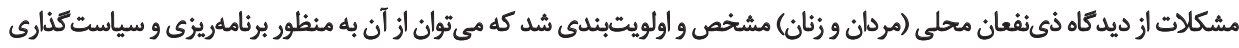

$$
\text { براى دستيابي به توسعه جامع روستانيى استئفاده كرد. }
$$

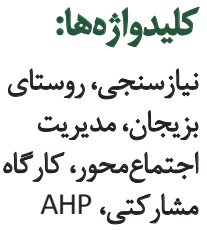

( ) مقدما

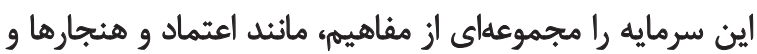

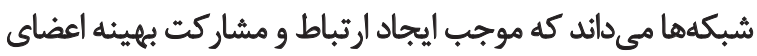

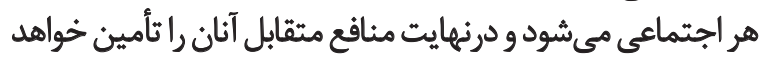

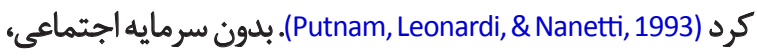

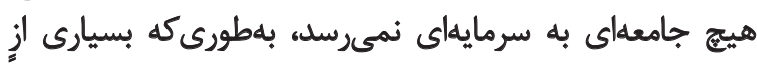

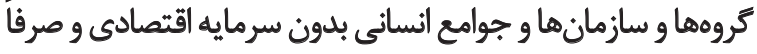

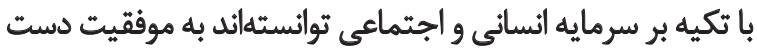

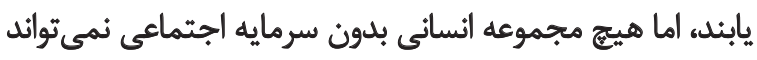
اقدامات مفيد و هدفمندى انجام دهد (Saboori, 2000).

بلهوركلى تعاريف متعدد و متفاوتى از سرمايه اجتماعى مطرح

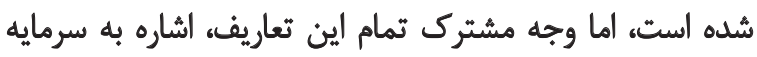

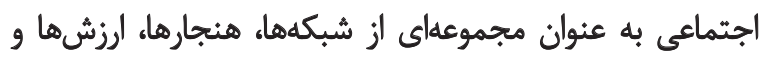

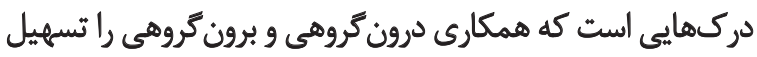

برنامههاى توسعله روستايى، جزئى از برنامهایى توسعه

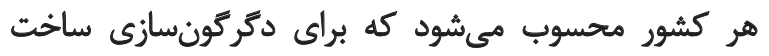

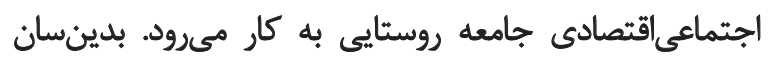

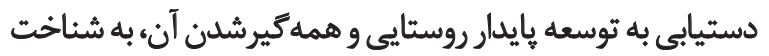

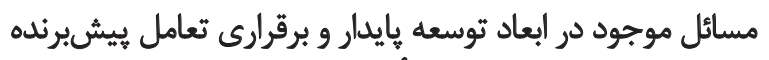

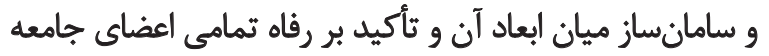

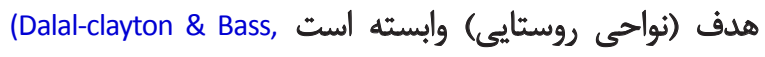
.2002; Anríquez \& Stamoulis, 2007)

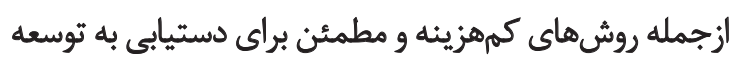

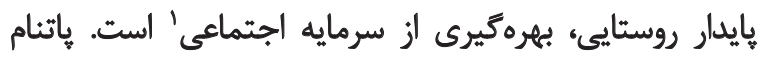
1. Social capital

: نويسئده مسئول:

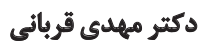

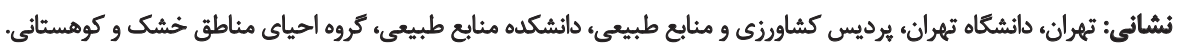

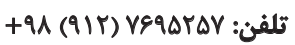
mehghorbani@ut.ac.ir بست الكترونيكي 
فرايند توسعه است و به طور بالقوه، بر توانمندسازى مشاركتى و

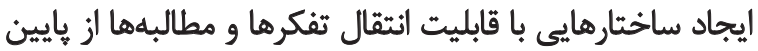

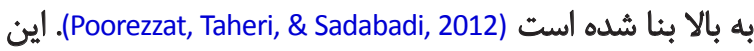

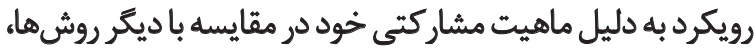
آثار توانمندسازى بيشترى دارد (Tavallaei \& Alipoor, 2014). اين باين

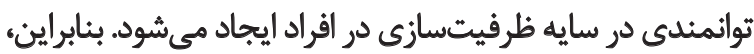

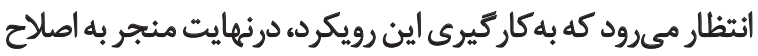

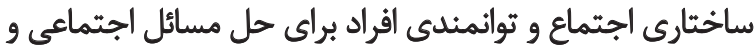
كاهش طرد اجتماعي شود (Shahcheraghi \& Mirzaeian, 2014).

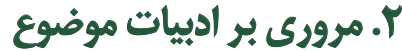

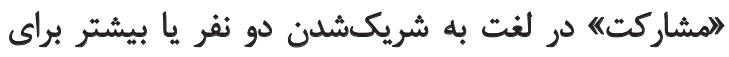

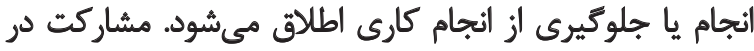

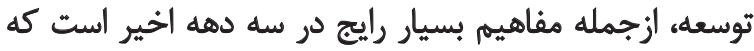

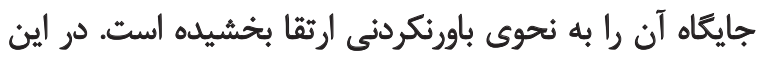

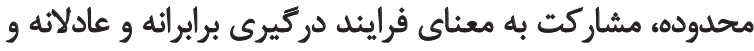

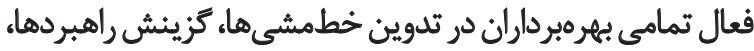

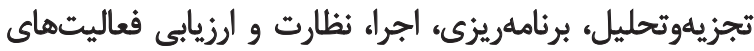

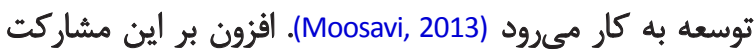

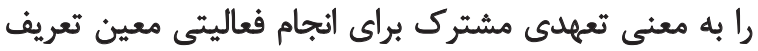

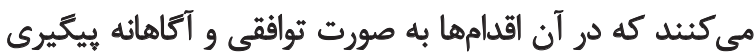
مىشود (Sharifian sani, 2002).

مشاركت با توزيع مجدد قدرت سياسى و اقتصادى در مسير

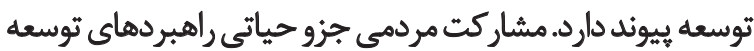

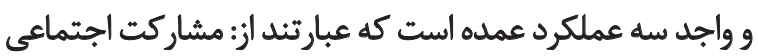

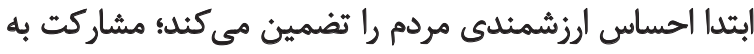

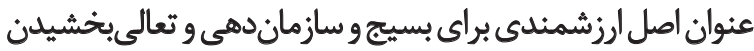

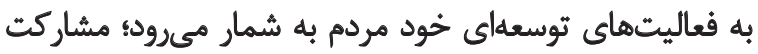

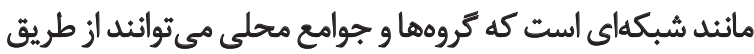

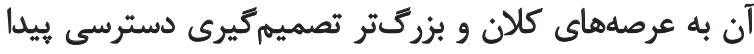

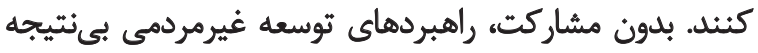

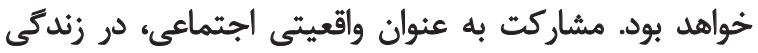

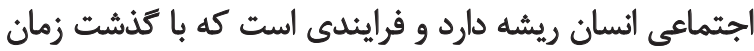
دكركون شده و تكامل يافته است (Dehghan \& Ghafari, 2006).

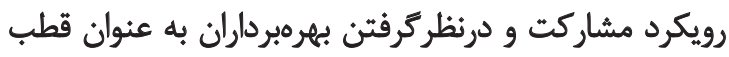

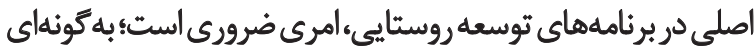

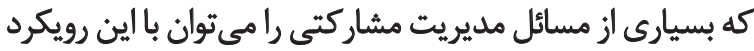
حلوفصل كرد \& Mehrabi, Mohammadi, Mohseni Saravi, Jafari, Ghorbani, 2014; Ghorbani, Mehrabi, Servati, \& Nazari Samani,

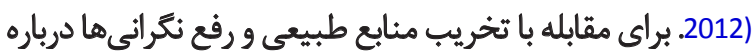

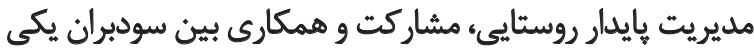

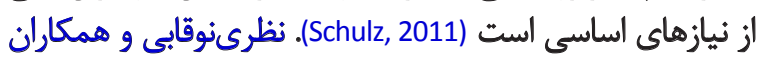

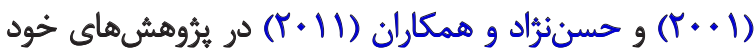

هي كند (Elmi, Sharepoor, \& Hoseini, 2006; Tajbakhsh, 2002). سرمايه اجتماعى يكى از اركان اساسى در توانمندسازى اجتماعى

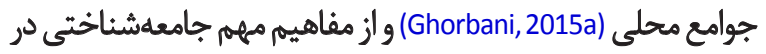

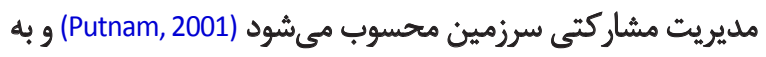

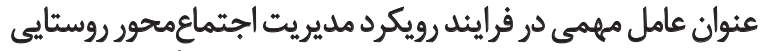

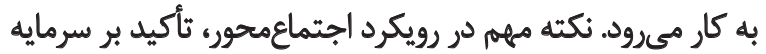

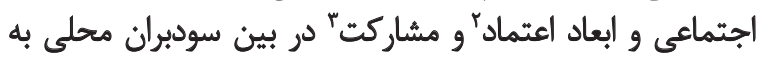
عنوان بازوى اصلى مديريت اجتماعححور يا مشاركت روستايى است. مشاركت يكى از ابعاد سرمايه اجتماعى و وجه اساسى و در

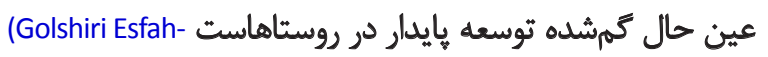

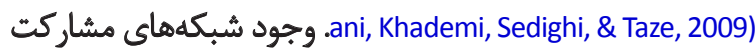

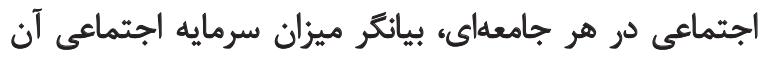

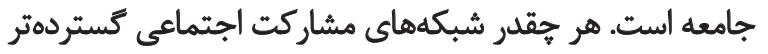

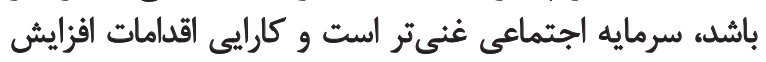

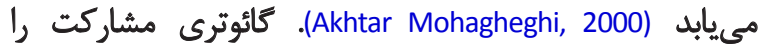

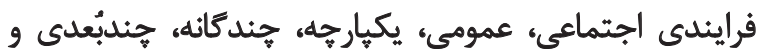

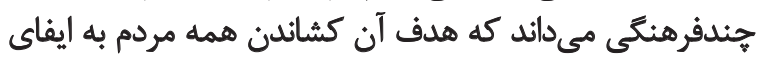

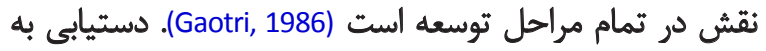

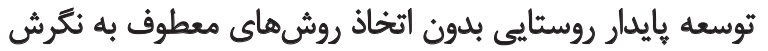

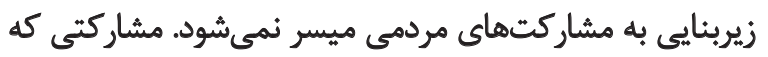

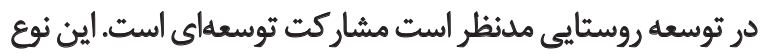

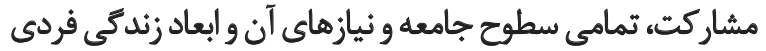
و كروهى را دربر مى كيرد (Oakley \& Marsden, 2002).

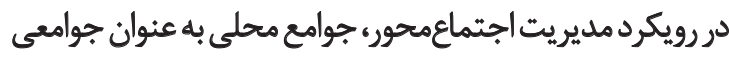

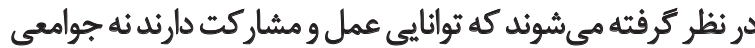

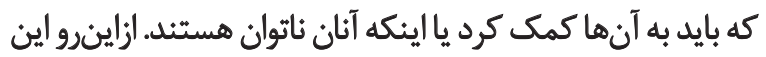

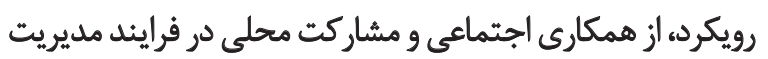

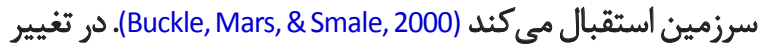

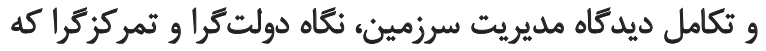

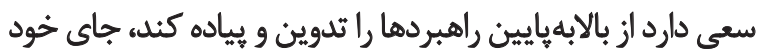

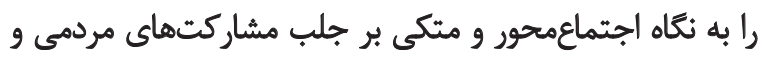

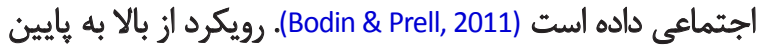

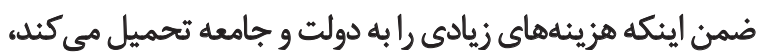

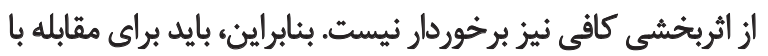

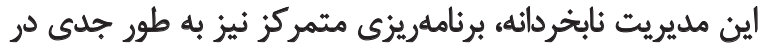
دستوركار قرار كيرد (Rafieian \& Motahari, 2012).

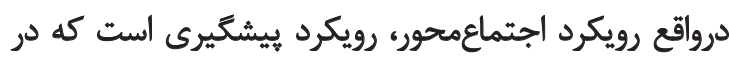

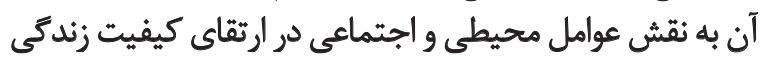

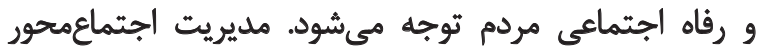

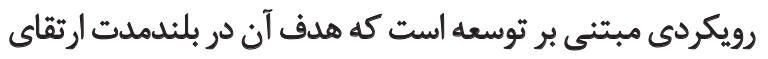

2. Trust

3. Collaboration 
منظور بررسى ظرفيت مشاركتيذيرى ساكنان شهرى، ميزان

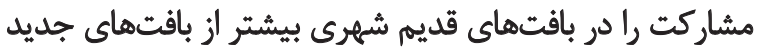
تخمين مىزند - Dobaran, Tavakolinia, Gholami, \& Danesh)

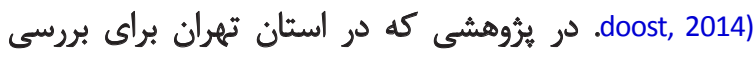

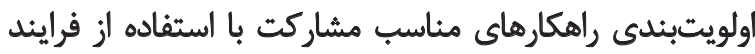

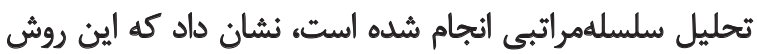

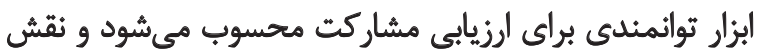

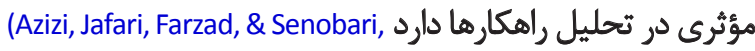

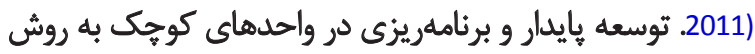

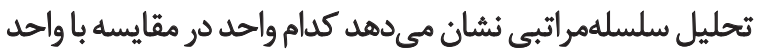

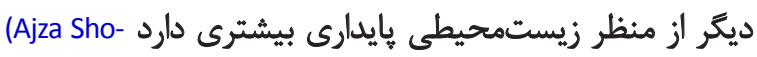
.koohi \& Moradi, 2013)

$$
\begin{aligned}
& \text { r. روششناسى تحقيق } \\
& \text { معرفي منطقه بروسى شده }
\end{aligned}
$$

روستاى بزيجان در دهستان باقر آباد در بخش مركزى شهرستان

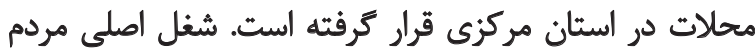

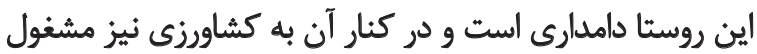

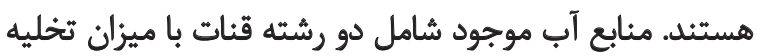

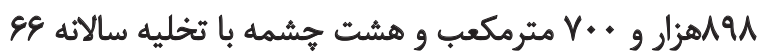

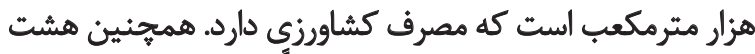

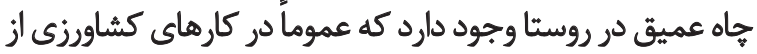

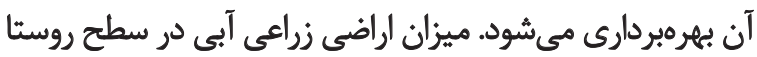

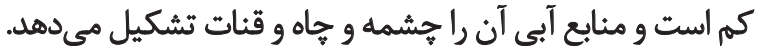

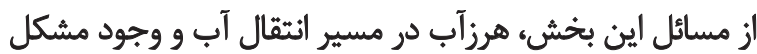
در قدات است (Ghorbani, 2015b).

معرفى برورثه الكوى ايرانى مشاركت و تواثمثلدسازى جوامع محلى با رويكرد شبكهنهاى اجثماعى (S.N.C.E.I.P)

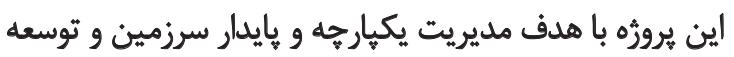

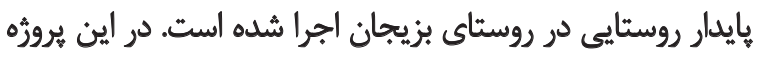

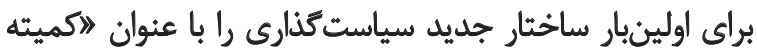

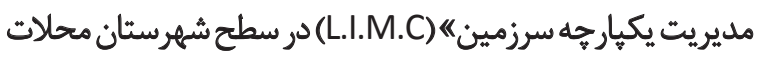

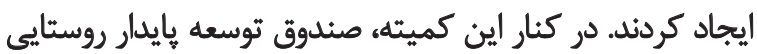

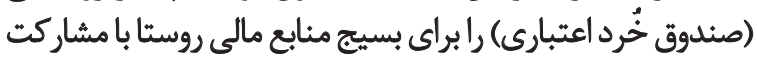

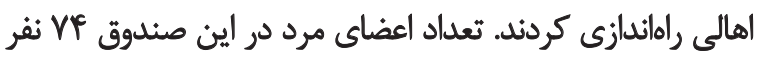

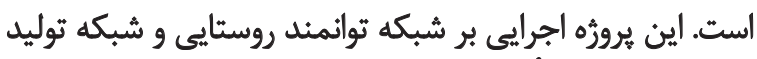

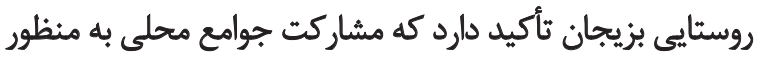

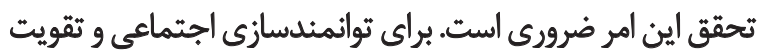

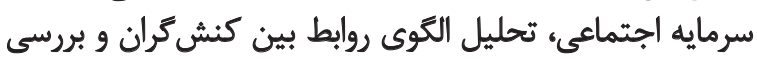

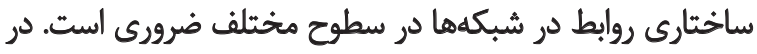

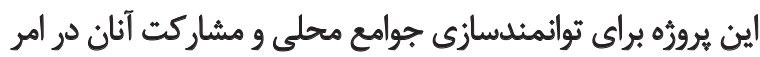

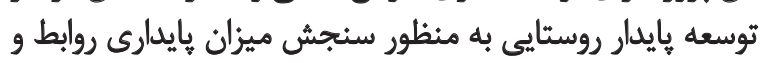

به اين نتيجه رسيدند كه ميزان رضايت از طرحها و يرورههاى

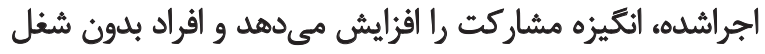

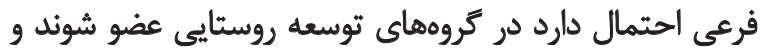

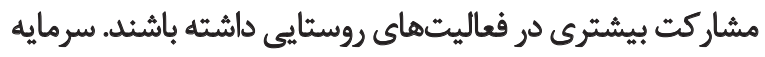

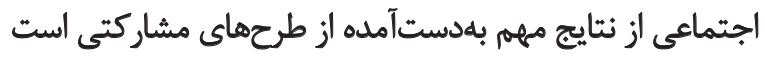

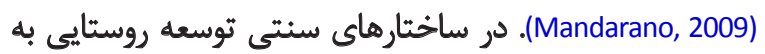

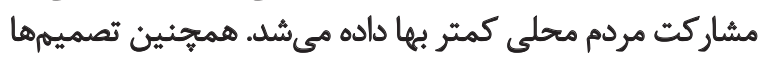

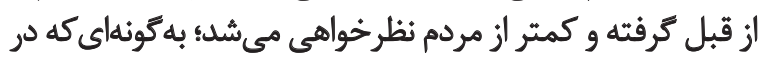

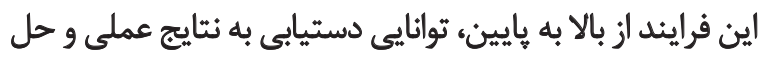

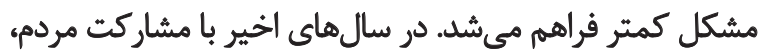

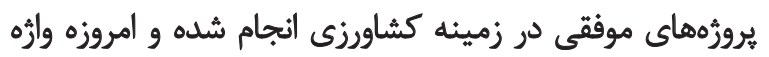

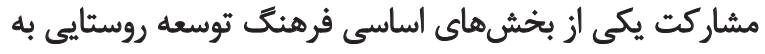
شمار مى آيد (Azkia \& Ghaffari, 2004).

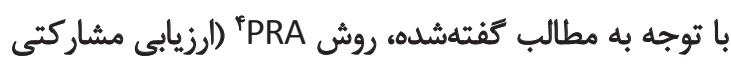

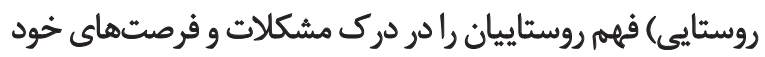

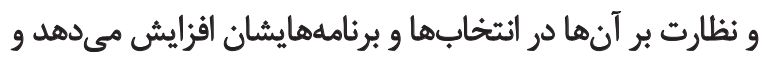

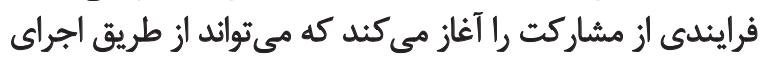

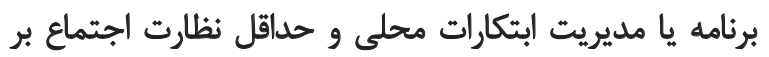

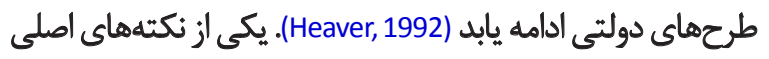

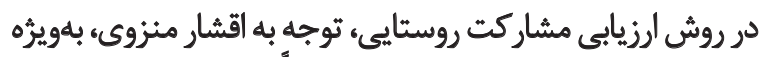

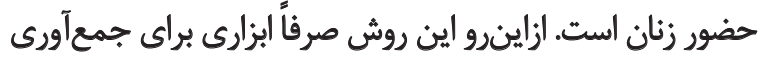

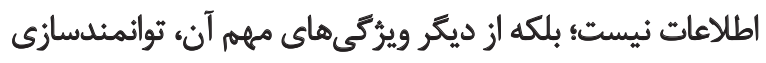

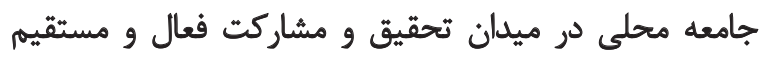

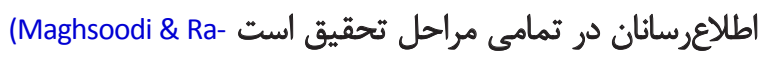
افزايش اعتماديهف himi, 2008)

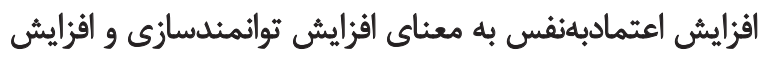

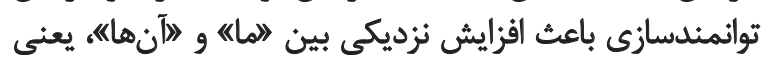
ذوبشدن سريعتر يخهاست (Chambers, 2003).

براى تحليل و ارزيابى نيازسنجى مشاركتى نياز است ثان بين

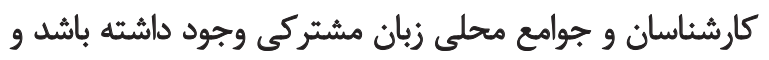

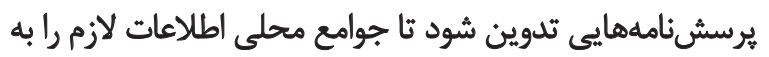

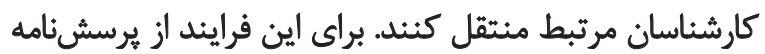

$$
\text { AHP }
$$

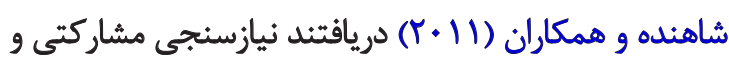

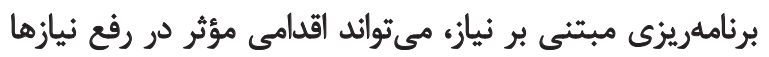

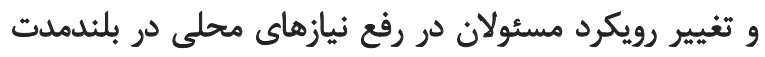

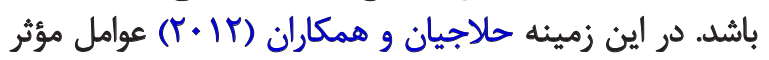

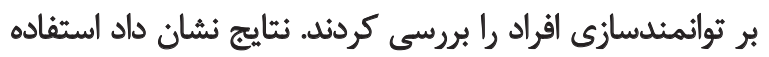

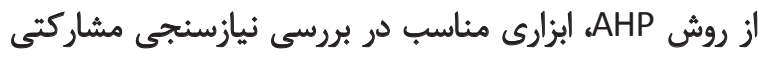

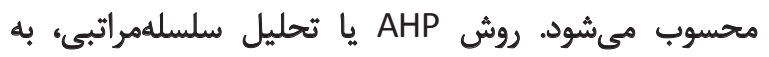

4. Participatory Rural Appraisal (PRA)

5. Analytical Hierarchy Process (AHP) 
r. مطالعه مبانى نظرى و رصد الكوهاى موفق در حوزه

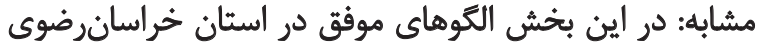
به منظور نشاندادن التوى موفق به به روستاييان ارائه شد تان نغرش صحيحى كسب كنئد؛

r. طراحى ابزٔار نيازسنجى بر اساس مبانى و القوهاى

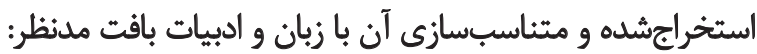

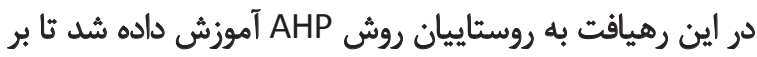
اساس روش مشخص و علمى، نيازهاى خود را شناسايى كنئد؛

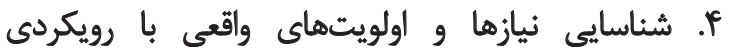

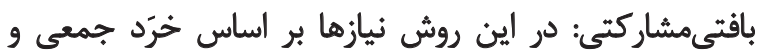

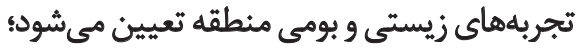

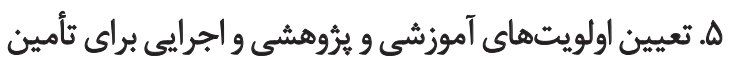

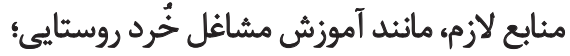

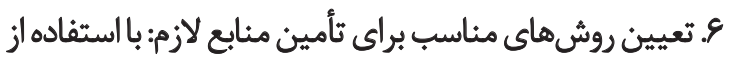

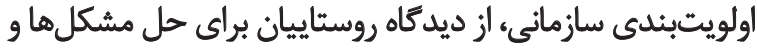

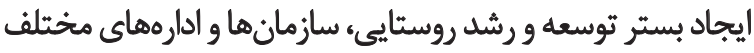
سطح شهرستان معرفى شد.

فرايند تحليل سلسلهمراتيب (AHP)

فرايند واكاوى سلسلهمراتبى يكى از روشهاى تصميمكيرى

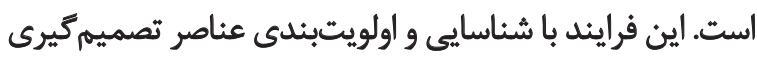

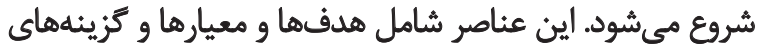

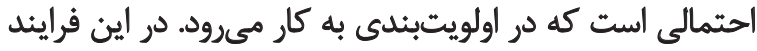

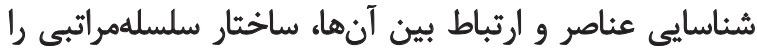

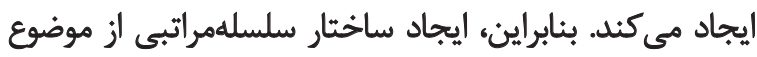

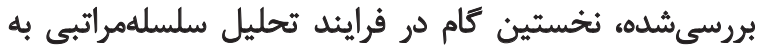

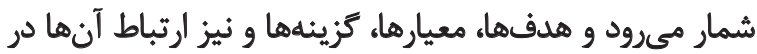

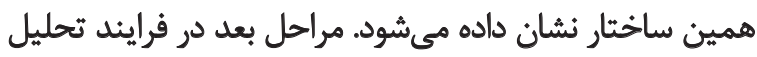

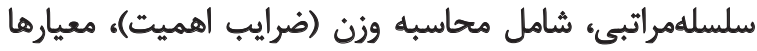

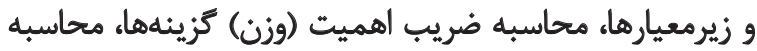

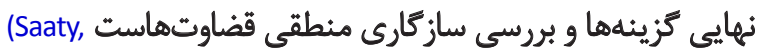
.1980; Saaty, 1990; Saaty, 1996)

فرايند رتبهبندى و اولويتبندى تزينهها در روش AHP دربركيرنده دو مرحله زير است:

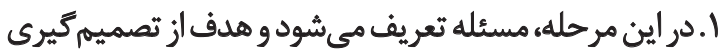

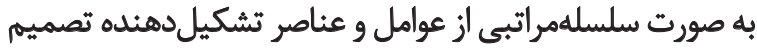

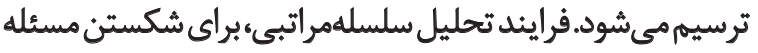

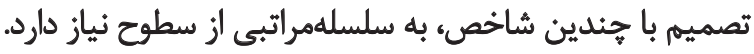

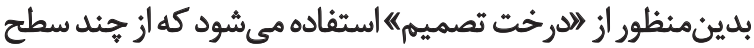

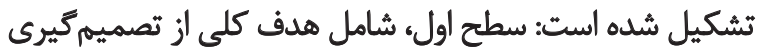

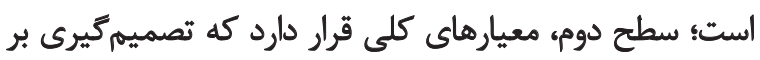

تحليل سرمايه اجتماعى درون كروهي، از رويكرد تحليل شبكههاي اجتماعى (SNA) استفاده شده است (Ghorbani, 2015b).

$$
\text { روش ارزيابى مشاركتى روستايى }
$$

اصطلاح تسهيلكَرى، وارَّاى است كه در نيمه دوم قرن بيستم

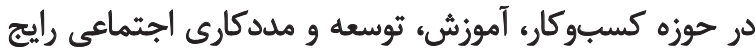

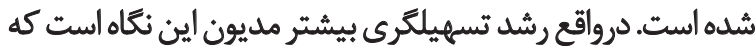

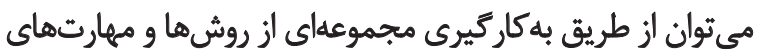

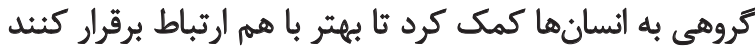

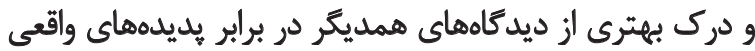

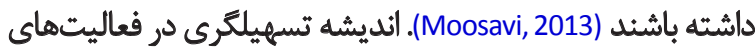

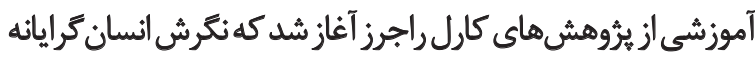

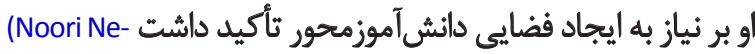

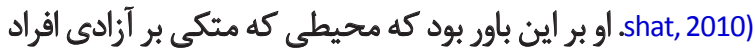

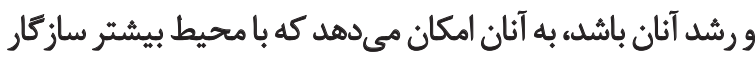
شوند و در مديريت محيط بهتر مشاركت كنند.

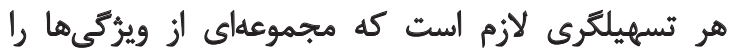

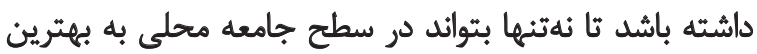

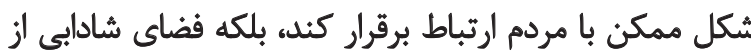

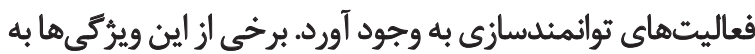

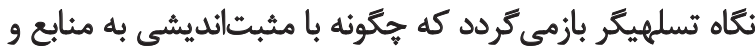

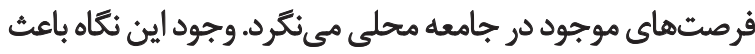
مىشود تسهيلكَر بهتر بتواند اعتماد افراد را به خود جرد جلب كند.

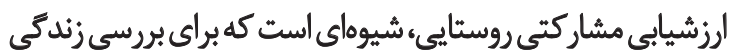

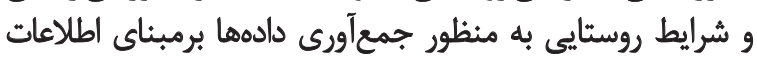

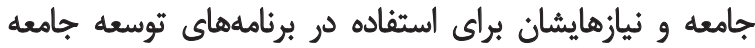

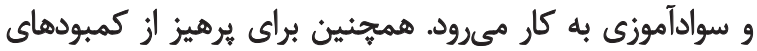

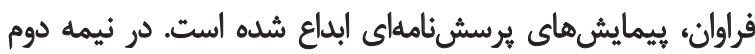

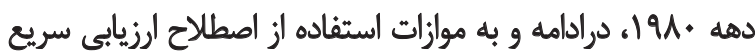

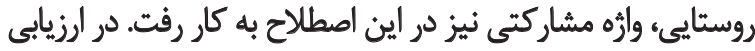

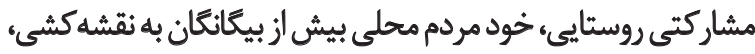

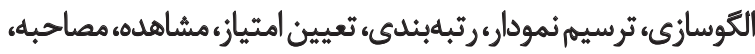
تحليل و برنامهريزى دست مىزئند (Chambers, 2003).

نيازسنجى راهى براى جمعآورى اطلاعات است كه بر اساس آن

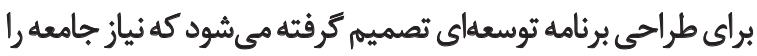

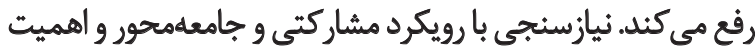

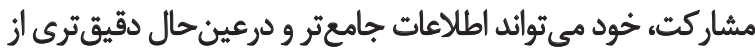

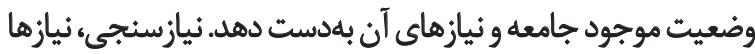

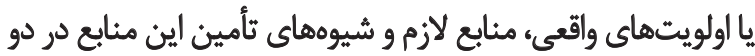
سطح فردى و سازمانى در شش مرحله انجام مى لأودائ 1.درك بافت مدنظر براي انجام نيازسنجى: در اين بخش بافت روستايى بزيجان مدنظر قرار ترفت؛ 
جدول ا. جدول نُهمتيتتى مقايسه دوبهدويى شاخصها (Saaty, 1990).

\begin{tabular}{|c|c|c|}
\hline توضيح & تعريف & 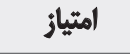 \\
\hline در تحقق هلف، دو شاخص اهميت مساوى دارند. & 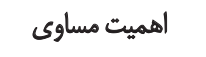 & 1 \\
\hline تجريه نشان ميدهل براي تحقق هلف اهميت أ اندكى بيش از ز است. & الهميت أندكى ييشتر & $r$ \\
\hline تجربه نشان هيدهل كه براى تحقق هلف، اهميت أبيش از ز است. & اهميت بيشتر & $\Delta$ \\
\hline تجربه نشان ميدهل براى تحقق هلف، اهميت أ خيلى بيشتر از ز است. & اهميت خيلي بيشتر & $\checkmark$ \\
\hline اهميت خيلي بيشتر أ در مقايسه با ز به طور قطعى اثبات شده است. & الهميت مطلق & 9 \\
\hline هنكامى كه حالت ميانه وجود دارد. & برترى هاى بينايين & A, g, f. T \\
\hline
\end{tabular}

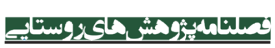

$$
\text { ترسيم نقشه اجتماعى و منابع" }
$$

به منظور ترسيم نقشه اجتماعى، در جلسههايى كه با حضور

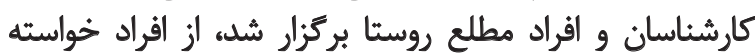

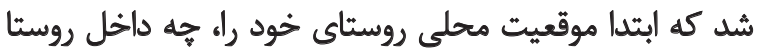

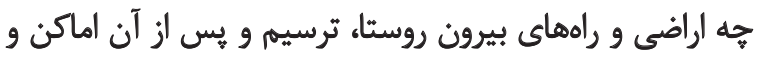

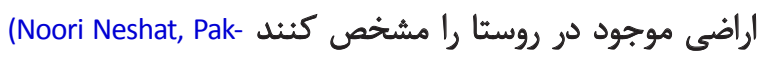
(zadmanesh, Esmaeilian, \& Goojan Samani, 2009)

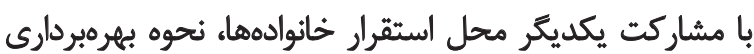

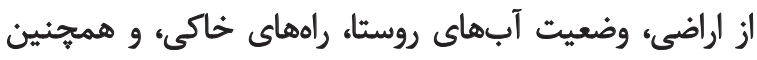

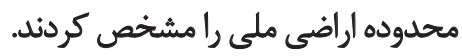

$$
\text { v }
$$

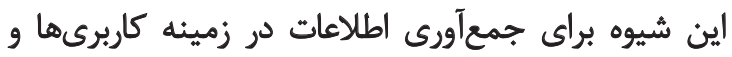
يوشش اراضى و فرصتها و موانع موجود درباره هر يك أز منابع

6. Social/ resource mapping

7. Village transect

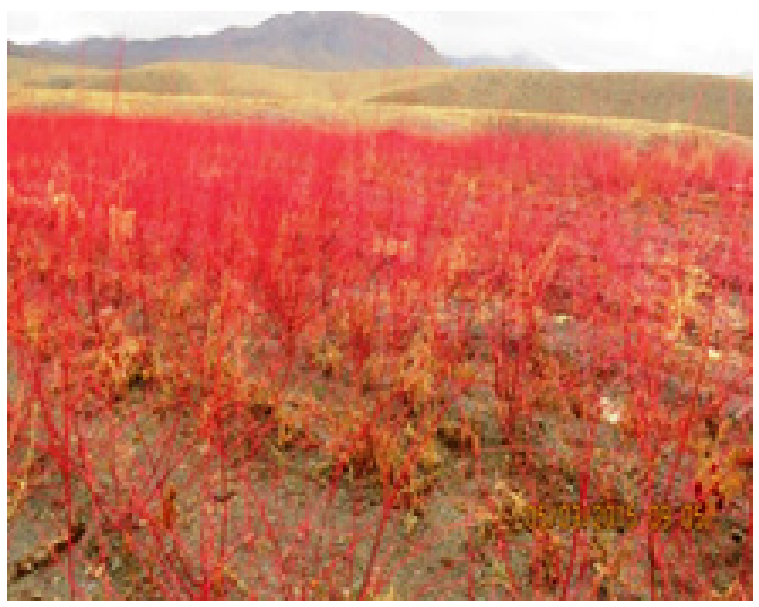

$$
\text { أساس آنها صورت مى كيرد. }
$$

r. در اين مرحله، روستاييان مقايسههايى را بين معيارهاى

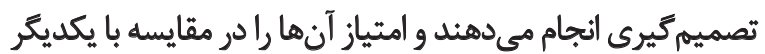

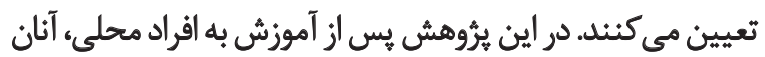

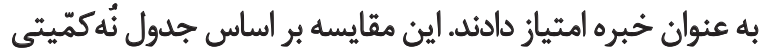

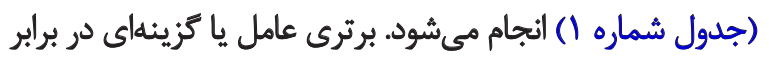

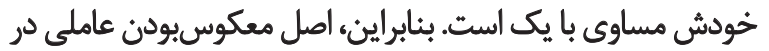

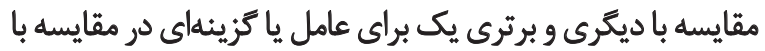

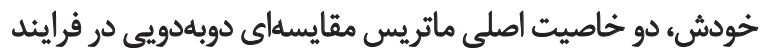

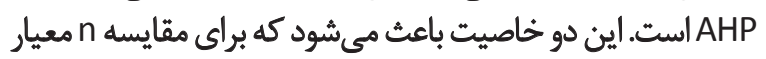

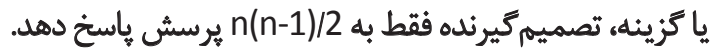

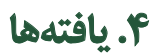
كاركاههاى مشاركتى نيازسنجى بدينشرح بركزار شد:

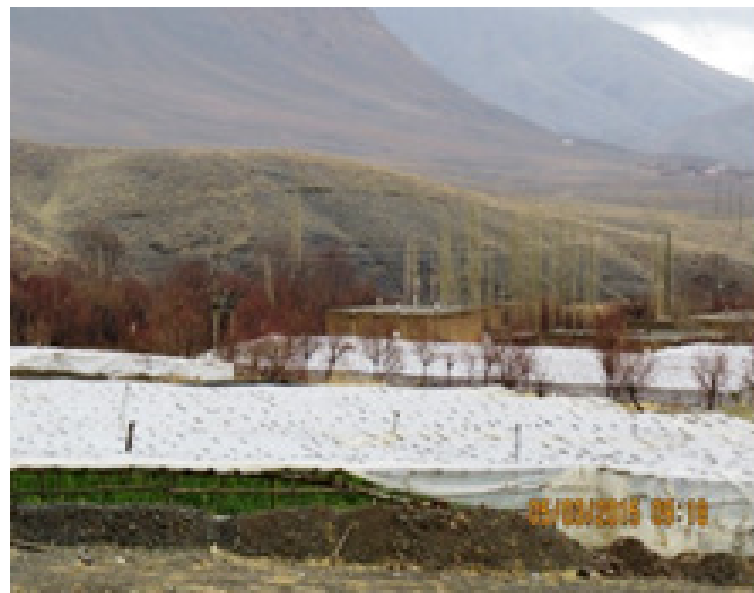

تصوير ا. كردش روستايى روستاى بزيجان. 


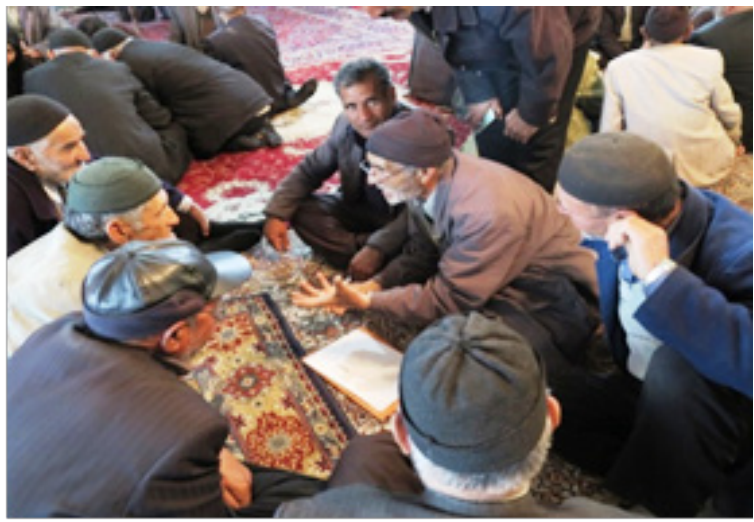

:

$$
\text { تصوير ". بررسى روند تغييرهاى روستاى بررسى شيده. }
$$

تفكيك جهار فصل در روستا رايج است (تصوير شماره Y).

$$
\text { بروسى روند تغنييرها }
$$

براى كسب اطلاع درباره تاريخ طبيعى روستادر سال هاى اخير،

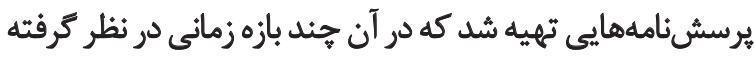

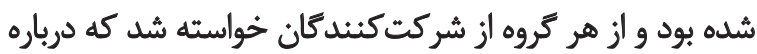

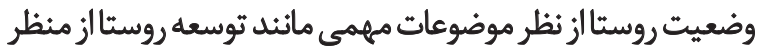

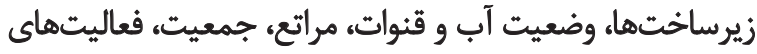

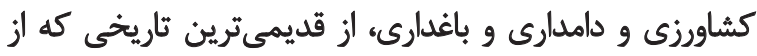

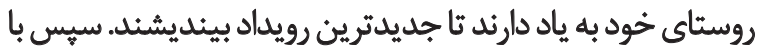

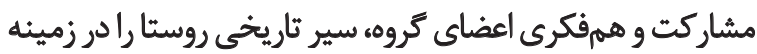

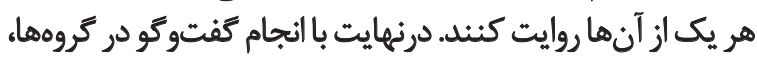

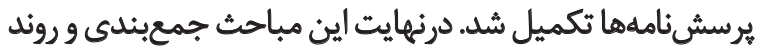

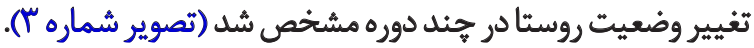

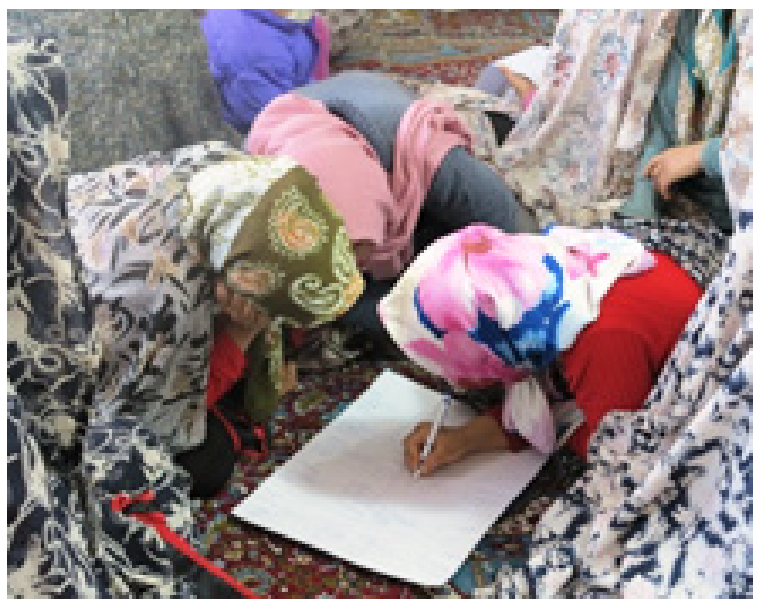

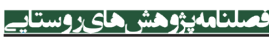

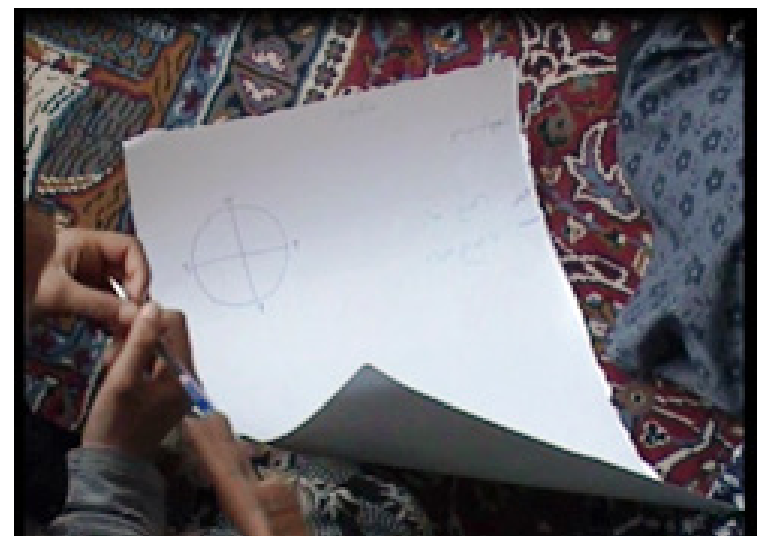

ت

تصوير Y. استخراج برنامه روزمره روستاي بزيجان.

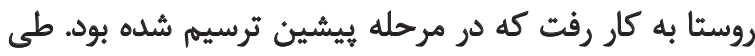

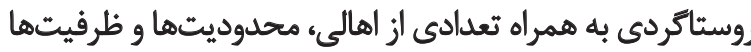

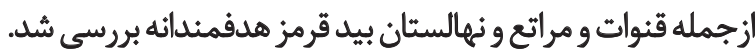

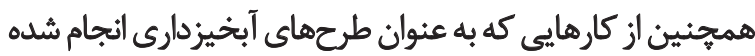

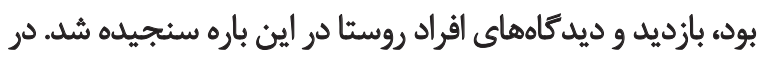

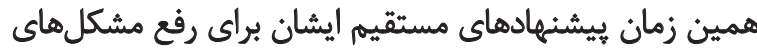
عمده روستا نيز دريافت و يادداشت شد (تصوير شماره ل).

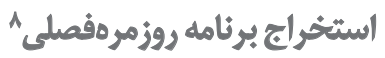

در كاركاه جهارم به منظور بررسى زمانبئدى فعاليتهاى

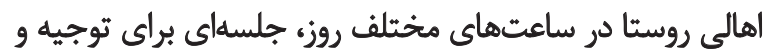

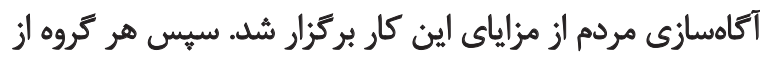

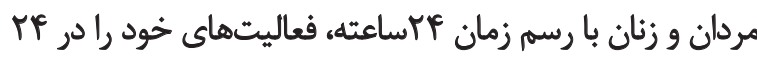

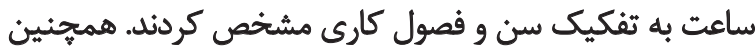

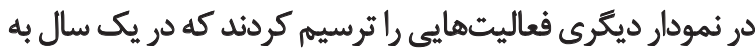

\section{Daily routine / schedule}

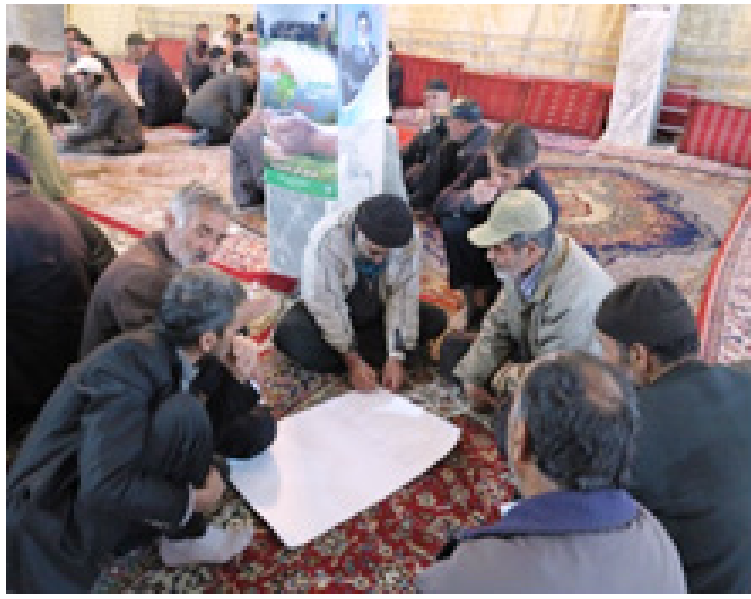

تصوير f. ترسيه درخت مشكلات در روستاى بزيجان در كروه مردان و زنان. 


\section{الولويثبندى مشكلها و ئيازها}

به منظور اولويتبندى مشكلها و نيازها، از تحليلكران خواسته

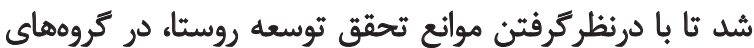

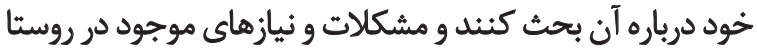

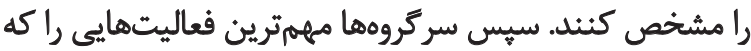

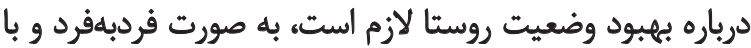

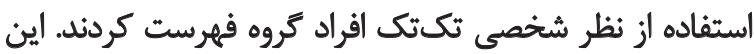

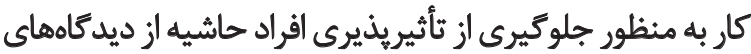

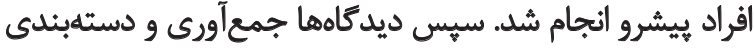

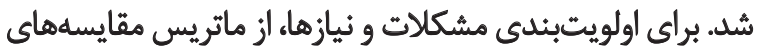

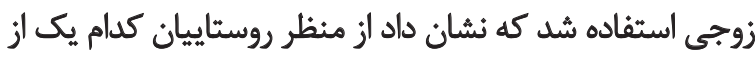

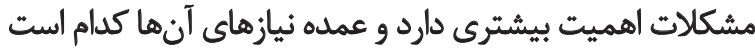

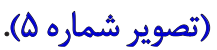

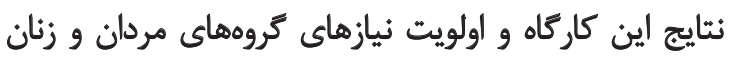

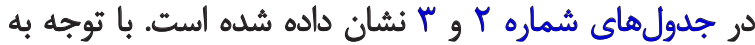

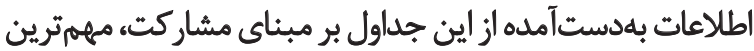

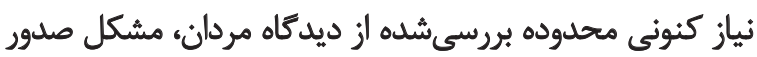

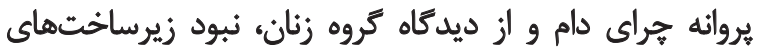

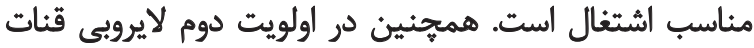

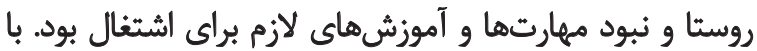

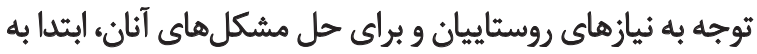

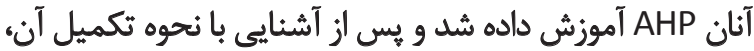

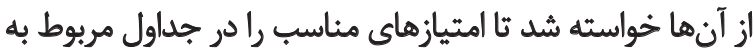

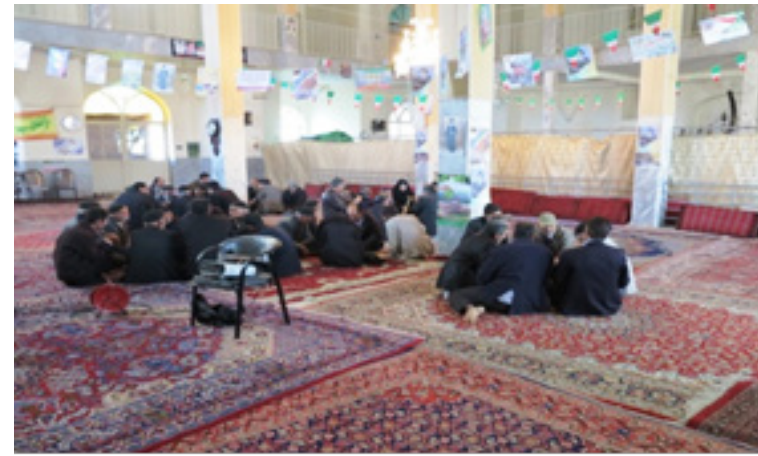

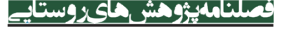

تصوير ه. بركزارى كاركاههاى اولويتبندى مشكلها و نيازهاى روستاى بزيجان.

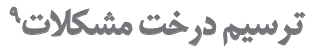

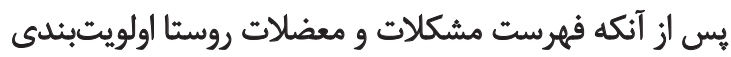

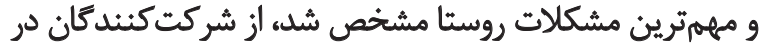

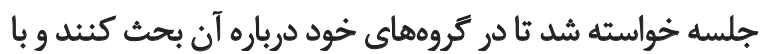

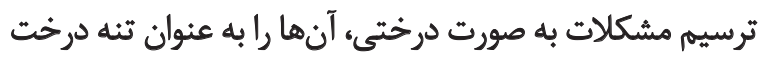

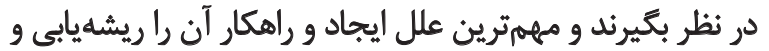

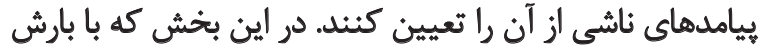

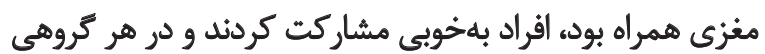
درخت مشكلات ترسيم شد (تصوير شماره f).

9. Problem tree or cause effect analysis

جدول r. نيازسنجى مشاركتى مردان روستاى بزيجان برمبناي اولويتبندى و بيشترين تثاضا.

\begin{tabular}{|c|c|c|}
\hline امتياز & نيازسنجى مشاركتى & رديف \\
\hline 1. & مشكل يروائه جراى دام & 1 \\
\hline 9 & لايروبى قثات & r \\
\hline$\wedge$ & ثبود دكتر و بهيار & $r$ \\
\hline$r$ & هشكل هسكن جواثان & $r$ \\
\hline 8 & كشت ديهزارهاي كمبازده & a \\
\hline$\Delta$ & نداشتن زمين آبى كافى براى زراعت & 8 \\
\hline$\Delta$ & حمله كرازهاى وحشى & $\checkmark$ \\
\hline F & مشكل دفترجه روستايى & $\wedge$ \\
\hline$\varphi$ & مشكل معابر روستايى & 9 \\
\hline$\varphi$ & واكسيناسيون دام & 1. \\
\hline$r$ & تهيه كود كشاورزى & 11 \\
\hline 1 & مشكل وام بانكهاى دولتى & ir \\
\hline
\end{tabular}


جدول r. نيازسنجى مشاركتى زنان روستاى بزيجان برمبناي اولويتبندى و بيشترين تقاضا.

\begin{tabular}{|c|c|c|}
\hline 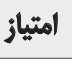 & نيازسنجى مشاركتى & رديف \\
\hline$\Delta$ & شاغلنبودن زنان & 1 \\
\hline f & ثبود مهارتها و آموزش هاي لازم براي اشتغال & r \\
\hline r & ثبود امكائات مرتبط با سلامت و درمان مثاسب (بيار و يزشى) & r \\
\hline 1 & نبود امكانات و وسايل حملونقل عموهى & f \\
\hline 1 & يرداختششلن وامهاي خوداششغالى & $\Delta$ \\
\hline 1 & نبود مقطع دييرستان براى ادامه تحصيل زنان & $\varepsilon$ \\
\hline
\end{tabular}

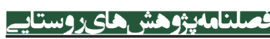

كاركاه نيازسنجى وارد نرمافزار EXPERT CHOICE يك از نياز ها مشخص شئرسئ

همانطوركه تصاوير شمارههاى ل و 1 ماتريس نيازسنجى

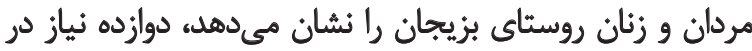

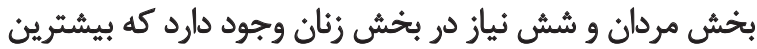

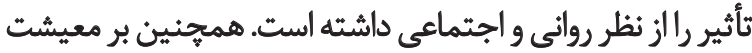
كروههاي روستاييى اثر كذاشته است

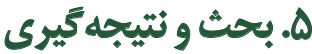

نيازسنجى مشاركتى زنان و مردان روستاي بزيجان، نمونه

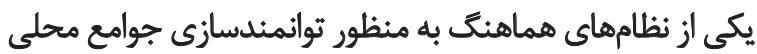

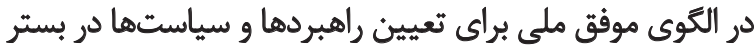

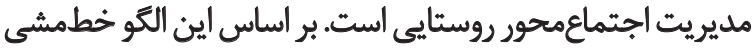

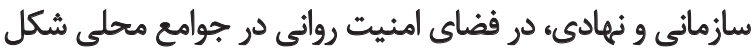

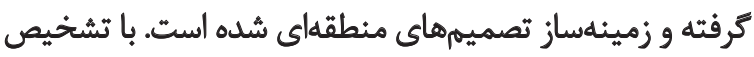

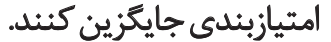

در زمينه بررسى بينشها و ديدكامهاى تروههاى روستايى

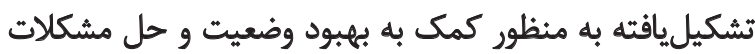

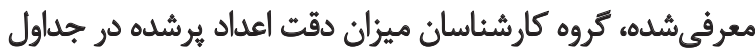

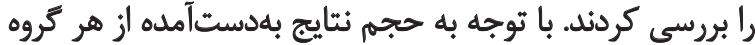

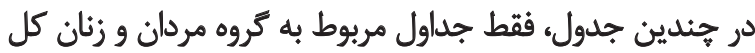

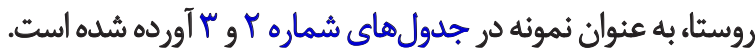

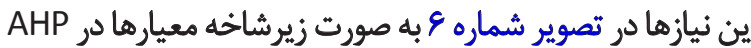

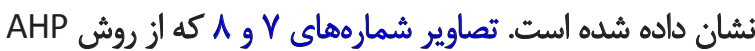

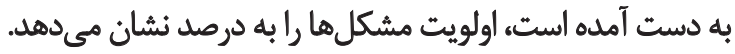
در انجام اين يرورثه، گروه تسهيلكر با حضور مداوم در روستاي

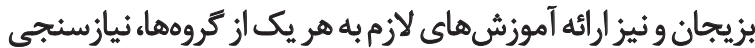

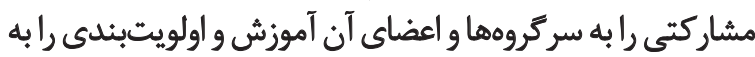

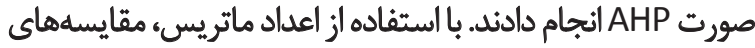
زوجى گروههاى مردان و زنان روستايى بهدستآمده از نتايج

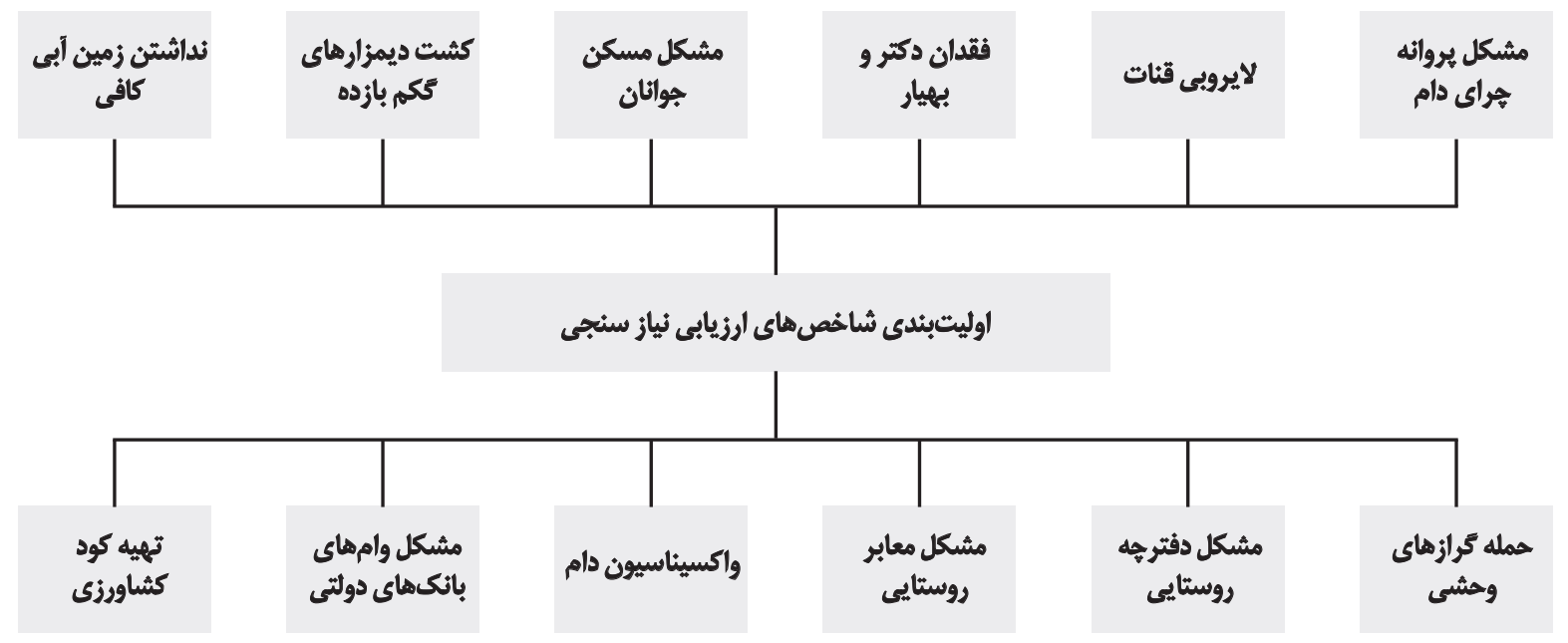




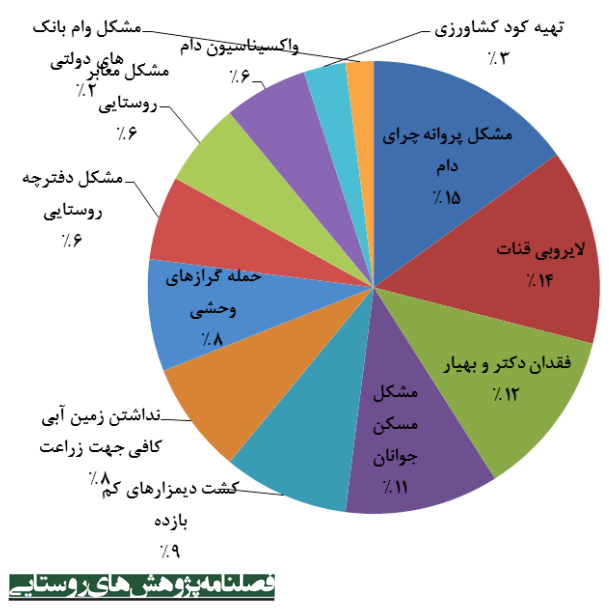

تصوير A. نيازسنجى مشاركتى مردان روستاى بزيجان.

مى كوشد تا مشاركت همه جانبه روستاييان راز إبتداي تعيين نيازها

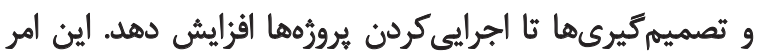

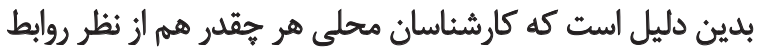

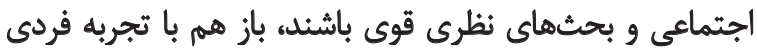

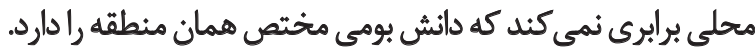

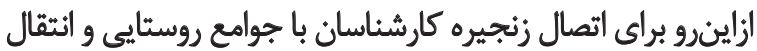

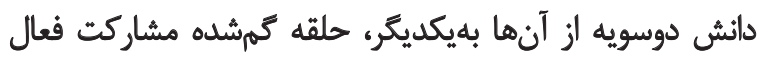

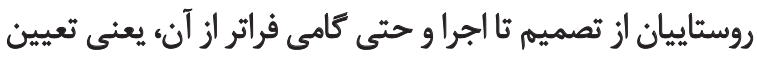

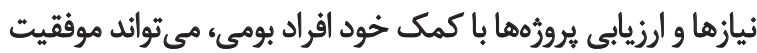

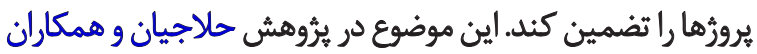

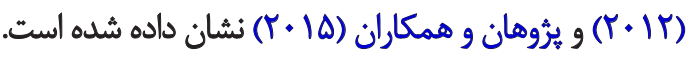

اينكه تا خه ميزان تعيين نيازها با ساختار جامعه روستايى

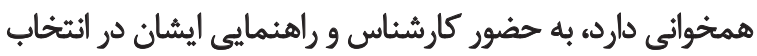

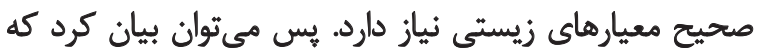

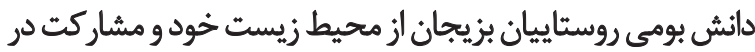

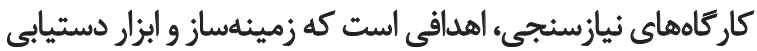

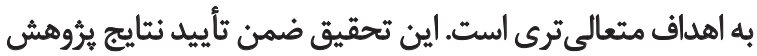

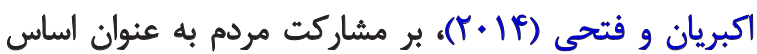
توسعه اجتماعى تأكيد و آن را ابزارى كار آمد معرفى مي كئد

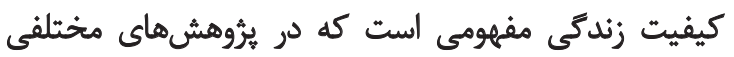

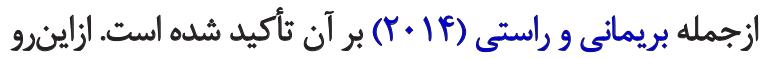

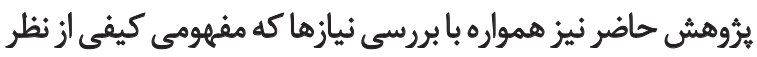
رضايتخاطر روستاييان است (Hajinejad, Paydar, \& Byad, 2015)،

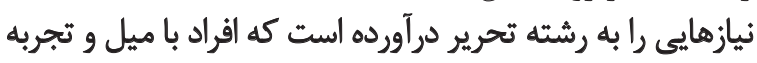

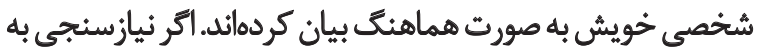

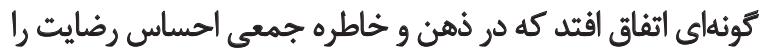

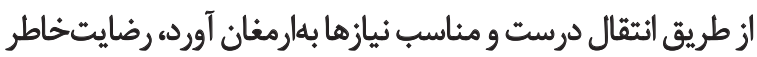

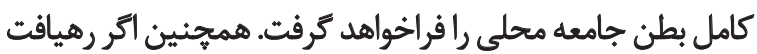

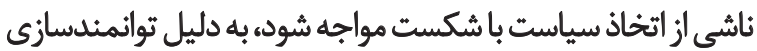

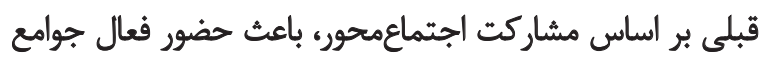

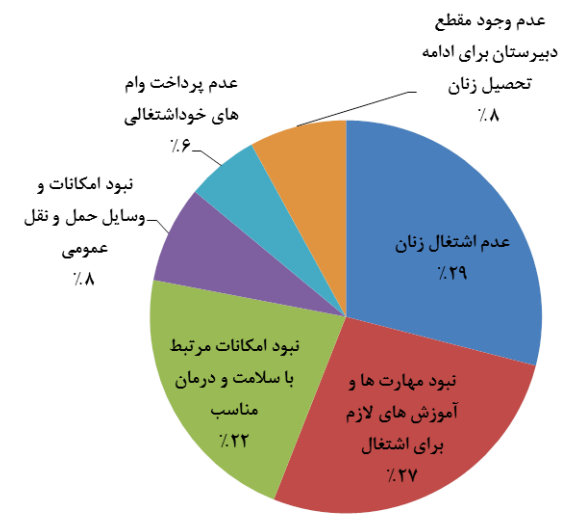

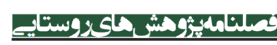

تصوير У. نيازٔسنجي مشاركتي زنان روستاى بريجان.

درست و بهموقع نيازهاى سودبران محلىى افزون بر تصميمسازى

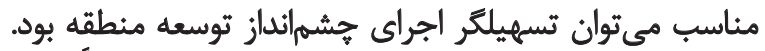

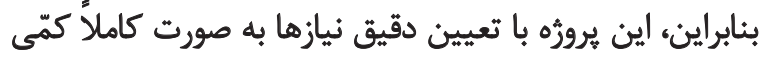

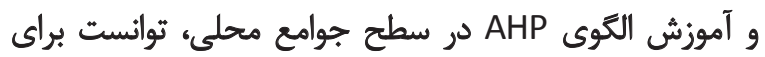

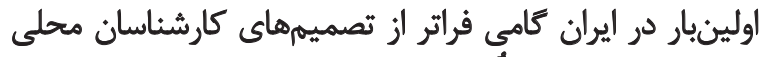

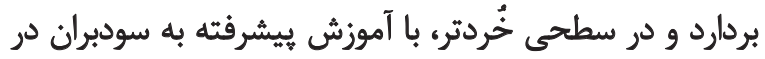

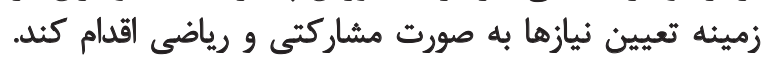

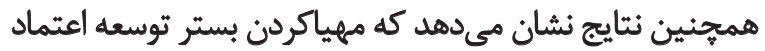

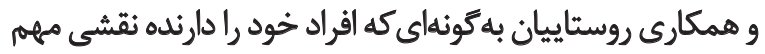

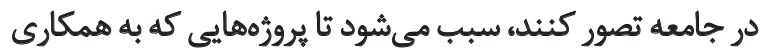

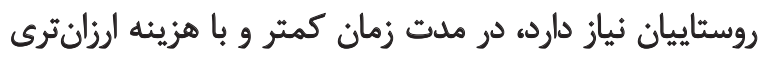

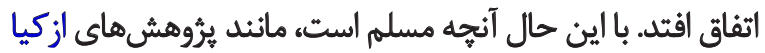

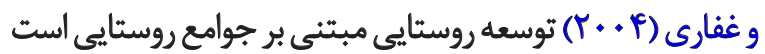

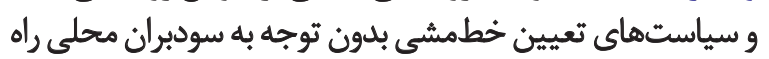
به جايى نخواهد برد.

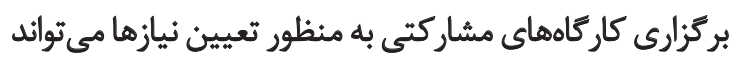

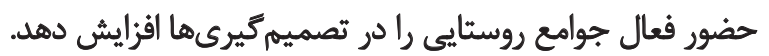

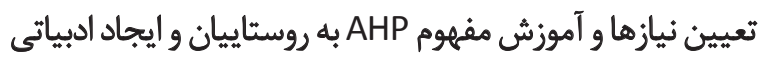

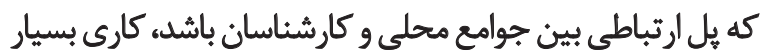

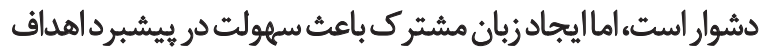

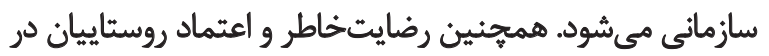

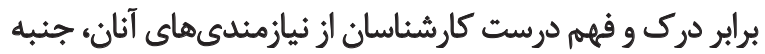

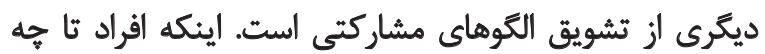

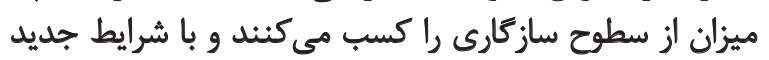

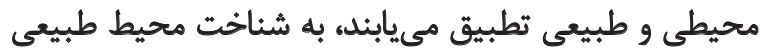
خود روستاييان و مشاركت فعال نياز دارد.

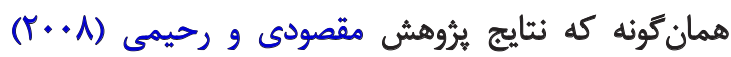

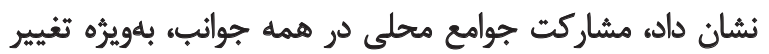

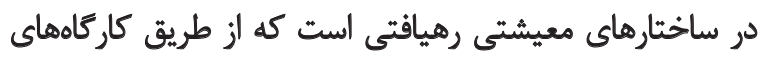

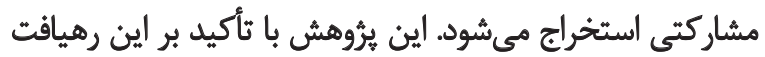




\section{References}

Ajza Shokoohi, M., \& Moradi, F. (2013). [Comparative study of stability in Sarab and Sajad parishes in Mashhad using AHP and Delphi (with the participation of Mashhad Municipality) (Persian)]. Journal of Geography and Regional Development, 10(19), 95117.

Akbarian, M., \& Fathi, L. (2014). [People participation, basis of social development (Persian)]. Journal of Research and Health, 2(1), 7-8.

Akhtar Mohagheghi, M. (2000). [Social capital (Persian)]. Tehran: Mehdi Akhtar Mohagheghi.

Anríquez, G., \& Stamoulis, K. (2007). Rural development and poverty reduction: Is agriculture still the key. Journal of Agricultural and Development Economics, 4(1), 5-46.

Azizi, N., Jafari, P., Farzad, V., \& Senobari. M. (2011). [Investigate ways public-private partnership in education and selection of the most appropriate mechanism using Analytical Hierarchy Process (AHP) (Persian)]. Journal of Educational Planning, 1 (1), 7-31.

Azkia, M., \& Ghaffari, G. (2004). [Rural development with emphasis on rural community in Iran (Persian)]. Tehran: Ney publication.

Barimani, F., \& Rasti, H. (2014). [Comparative study of accuracy rate of fuzzy AHP and classical AHP methods for ranking indicators affecting on the quality of life (Case study: Mahban village, township Nikshahr township) (Persian)]. Journal of Geography and Development, 12(34), 1-14.

Bodin, O., \& Prell, C. (2011). Social networks and natural resources management. Cambridge: Cambridge University Press. doi: 10.1017/ cbo9780511894985

Buckle, P., Mars, G., \& Smale, S. (2000). New approaches to assessing vulnerability and resilience. Australian Journal of Emergency Management, 15(2), 8-15.

Chambers, R. (2003). Reflections on PRA experience. In A. Cornwall, \& G. Pratt, Pathways to Participation (pp. 36-40). Rugby: Practical Action Publishing.

Chambers, R. (2008). PRA, PLA and pluralism: Practice and theory. In P. Reason, \& H. Bradbury (Eds.), The SAGE Handbook of Action Research (pp. 297-318). Oxford: Sage Publishing.

Dalal-Clayton, B., \& Bass, S. (2002). Sustainable development strategies: A resource book. London: Earthscan Publication Ltd.

Dehghan, A., \& Ghafari, Gh. (2006). [Explaining the socio-cultural participation of students of medical universities in Tehran (Persian)]. Iranian Journal of Sociology, 6(1), 67-98.

Dobaran, E., Tavakolinia, J., Gholami, S., \& Daneshdoost, M. (2014). [Cooperative measurement of participating capacity in old and new city fabrics with AHP model (Case study: Hossaineyeh (old) and Ghaem Town (new) in Zanjan City) (Persian)]. Journal of Geography and Planning, 18(48), 123-48.

Elmi, Z., Sharepoor, M., \& Hoseini, A. (2006). [Social capital and its effects on the economy (Persian)]. Economic Research Journal, 40(4), 239-96.

Gaotri, H. (1986). Popular participation in development. Paris: UNESCO.

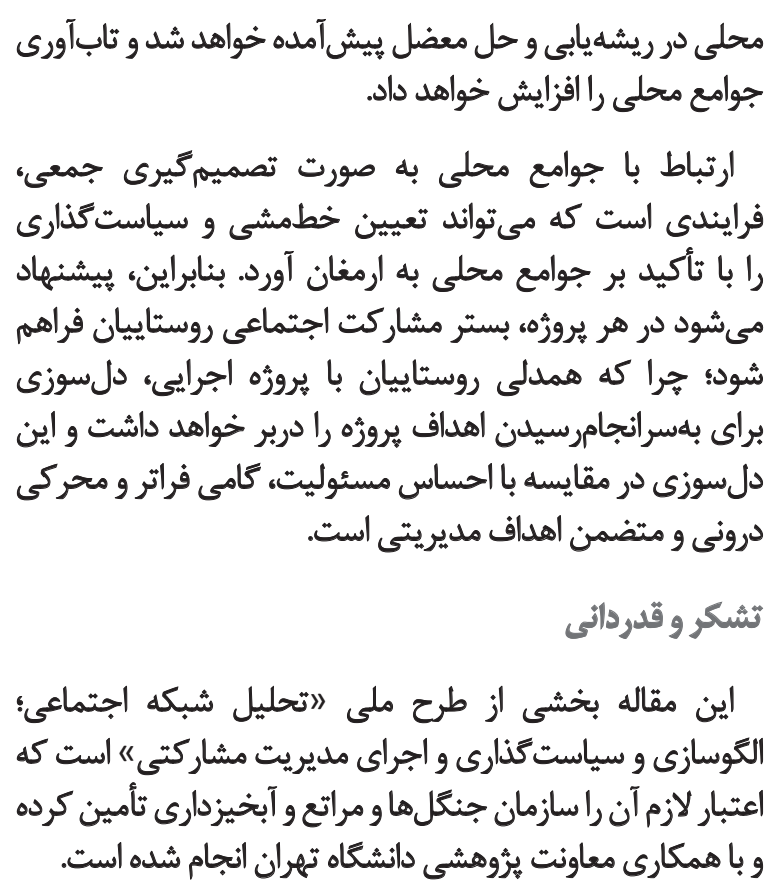


Ghorbani, M. (2015a). [Iranian model of participation and empowerment of local communities with the social network approach (Persian)]. Tehran: Tehran University Press.

Ghorbani, M. (2015b). [The plan of monitoring and evaluation of social media-policy in empowering local communities and comprehensive land management (Persian)]. Tehran: Tehran University Press.

Ghorbani, M., Mehrabi, A. K., Servati, M. R., \& Nazari Samani, A. A. (2012). [Evaluation of the demographic changes and its effectiveness in land use (Case study: Bala Taleqgan Region) (Persian)]. Journal of Range and Watershed Management, 63(1), 75-88.

Golshiri Esfahani, Z., Khademi, H., Sedighi, R., \& Taze, M. (2009). [The impact of social cohesion on the participation of rural people: A case study Gandoman Region, Boroujen City (Persian)]. Village and Development Quarterly, 12(1), 147-67.

Hajinejad, A., Paydar, A., \& Byad, H. (2015). [Analysis of income sources of rural municipalities (Dehyari) using participatory evaluation approach (Case study: Narjouiyeh Village in Jiroft County) (Persian)]. Journal of Rural Research and Planning, 4(2): 157-171.

Halajian, E., Sorayaei, A., \& Hoseinzade Ahmadi, F. (2012). [Studying affecting factors on empowerment of Islamic Azad University staff of Mazandaran province with AHP (Persian)]. Journal of Industrial Strategic Management, 9, 113-28.

Hasannejad, M., Kohansal, M. R., \& Ghorbani, M. (2011). [Factors affecting the participation of members of the rural development groups in promoting and preservation activities in international project of carbon sequestration (Persian)]. Agricultural Economics Research Journal, 2(7), 105-24.

Heaver, R. (1992). Participatory rural appraisal: Potential applications in family planning, health and nutrition programmes. $R R A$ Notes, 16, 13-21.

Maghsoodi, M., \& Rahimi, A. (2008). [Participatory rural appraisal methods: A case study: four villages in the Ovan region in Qazvin province (Persian)]. Rural Development Quarterly, 11(2), 91-118.

Mandarano, L. A. (2009). Social network analysis of social capital in collaborative planning. International Journal of Society \& Natural Resources, 22(3), 245-260. doi: 10.1080/08941920801922182

Mehrabi, A. A., Mohammadi, M., Mohseni Saravi, M., Jafari, M., \& Ghorbani, M. (2014). [Study of human driving forces affecting land use changes (Case study: Seyed Mahaleh and Drasra villages) (Persian)]. Journal of Range and Watershed Management, 66(2), 307-20.

Moosavi, M. T. (2013). [Introduction to social participation (Persian)]. Tehran: Jame'e Shenasan Publishing.

Nazari Nooghabi, S., Shabanali Fami, H., \& Irvani, H. (2011). [Factors affecting the level of satisfaction of students of practical agricultural training (College of Agriculture and Natural Resources, Tehran University) (Persian)]. Journal of Agricultural Economics and Development Research (Journal of Agricultural Sciences), 43(2), 271-9.

Noori Neshat, S. (2010). [Local research and planning for the preservation of the environment and natural resources (Persian)]. Tehran: Barge Zeitoon Publishing.

Noori Neshat, S., Pakzadmanesh, P., Esmaeilian, T.,\& Goojan Samani, B. (2009). [Facilitation in community-based rehabilitation; training manual for local facilitators (Persian)]. Tehran: Parson.
Oakley, P., \& Marsden, D. (2002). Approaches to participation in rural development [M. Mahmood Nejad, Persian trans]. Tehran: Jahad-e Sazandegi Publishing.

Pazhoohan, M., Fathi, H., \& Ghasemzade, B. (2015). [Application of participatory rural appraisal method in informal urban settlements planning (Case study: Settlements Islamabad, District 2 of Tehran) (Persian)]. Journal of Social Studies and Researches in Iran, 4(1), 93-118.

Poorezzat, A. A., Taheri, A. G., \& Sadabadi, A. A. (2012). [Leading sustainable nation-building strategy based on social justice (Persian)]. Political and International Research Quarterly, 4(11), 1-22.

Putnam, R. D. (2001). Bowling alone: The collapse and revival of American community. New York: Simon and Schuster.

Putnam, R. D., Leonardi, R. Y. \& Nanetti, R. (1993). Making democracy work: Civic traditions in modern Italy. New Jersey: Princeton University Press.

Rafieian, M., \& Motahari, Z. (2012). [Designing a model for studying the communitybased disaster risk management approach (Persian)]. Emergency Management, 1(1), 5-12.

Saaty, T. L. (1980). The analytic hierarchy process: Planning, priority setting, resource allocation. New York: McGraw-Hill International Book Company.

Saaty, T. L. (1990). Decision making for leaders: The analytic hierarchy process for decisions in a complex world. Pittsburgh: RWS publications.

Saaty, T. L. (1996). The analytic network process. Pittsburgh: RWS Publication.

Saboori, M. (2000). [Social theories foundation (Persian)]. Tehran: Ney publication.

Salehi Sedghiani, J. (2002). [Mathematical approach to AHP (Persian)]. Management Studies in Development and Evaluation, 8(31,32), $111-36$.

Schulz, R. W. (2011). Environmental literacy in science and society: From knowledge to decisions. New York: Cambridge University Press.

Shahande, Kh., Rajabi, F., Jamshidi, E., Majdzade, R., Aghajani, M., Majdzadeh, B., et al. (2011). [Final evaluation the results of the needs assessment in district 17 Tehran: Three years after the intervention (Persian)]. Hakim Journal, 14 (4), 219-26.

Shahcheraghi, F., \& Mirzaeian. A. (2014). [Study using the community-based approach in dealing with social issues (Persian)]. Paper presented at The National Conference on Social Problems of Iran Community-Based Approach, Iran, Isfahan, 22 December 2014.

Sharifian Sani, M. (2002). [Social capital: The main concepts and theoretical framework (Persian)]. Journal of Social Welfare, 1(2), 5-18.

Swanson, B. E., Bentz, R. P. \& Sofranko, A. J. (1997). Improving agricultural extension: A reference manual. Rome: Food and Agriculture Organization of the United Nations.

Tajbakhsh, K. (2002). [Trust, democracy and development (Persian)]. Tehran: Shiraze publication.

Tavallaei, H., \& Alipoor, F. (2014). [Participatory community-based research in the context of symbolic interaction theory (Persian)]. Paper presented at National Conference on Social Problems of Iran Community-Based Approach, Iran, Isfahan, 22 December 2014. 